\title{
Sorting at source and reusing: The case of construction and demolition waste in Turkey
}

\author{
V. Arslan*iD, S. Ulubeyli \\ Zonguldak Bulent Ecevit University, Department of Civil Engineering, Zonguldak, Turkey
}

\begin{abstract}
Construction and demolition waste (CDW) are one of the major environmental problems, and thus, should be considered as a significant component of sustainable built environment. In theory, there are three main options to overcome the CDW generation problem such as reducing, reusing, and recycling. However, in practice, it is a general behavior to implement the first two options to deal with CDW in many developing countries such as Turkey. The main reason behind this may be the high initial investment cost and compelling regulations concerning CDW recycling plants. Hence, sorting at source and reusing activities for CDW emerge as two beneficial alternatives for the Turkish construction industry. Based on these aforementioned arguments, the objective of the current study was to identify and examine the specific perspective of construction firms about sorting at source and reusing activities in the Turkish construction industry. Toward this aim, a questionnaire survey was applied to construction professionals in Turkey. According to the findings, for Turkish construction firms, having a CDW management plan is not common, using landfills to dispose the waste generated is popular, accessing to CDW recycling plants is very limited, sorting at source practices are rare, and sorting CDW in separate containers is not preferred. However, construction professionals have positive approach on sorting at source, reusing, and recycling of the CDW and excavation soil, and the selective demolition method before recycling. In addition, the financial and physical support of local authorities seem to be important for dissemination of CDW management applications in Turkey.
\end{abstract}

\section{Keywords}

Construction and demolition waste; Reusing; Sorting at source; Waste management; Turkey

Received: 20 November 2019; Accepted: 20 December 2019

ISSN: 2630-5771 (online) C 2019 Golden Light Publishing All rights reserved.

\section{Introduction}

Construction and demolition waste (CDW) can simply be described as the waste generated in the process of construction, renovation, and demolition of buildings and structures. CDW is one of the major environmental problems, and thus, should be considered as a significant component of sustainable built environment. The construction industry has a well-known reputation with its nonenvironmental-friendly activities [1] and the process of construction, renovation, and demolition of buildings and structures causes a mass amount of CDW. Therefore, up to date, many countries have implemented CDW management policies in order to prevent and/or minimize the amount of waste generated by the construction industry. In order solve or minimize CDW generation problem, in theory, there are three main options such as reducing, reusing, and recycling. In practice, it is a general behavior to implement the first two options

\footnotetext{
Corresponding author

Email: volkanarslan@beun.edu.tr
} 
to deal with CDW in many developing countries such as Turkey. The first option (that is, reducing), may have the potential to prevent the generation of CDW and to reduce the cost of recycling, transportation and disposal of CDW [2]. However, depending of several reasons, it may not always be possible to reduce CDW. In such cases, reusing or recycling emerge as the remaining options to deal with CDW. Reusing refers to the use of materials more than once in construction activities. There are two kinds of reusing practice, (i) using the material again for the same function and (ii) using the material as a raw material for a new function [2]. In case of practical impossibility of the reduction of CDW, reusing becomes the most desirable option since it has easy processes and needs minimum energy [3]. Finally, for recycling activities, there is a need for the recycling plants. The first CDW recycling plant in Turkey was established in 2006, and recently, there are only six active CDW recycling plants in Turkey. The main reason behind this may be the high initial investment cost and compelling regulations concerning CDW recycling plants. For this reason, difficulties in accessing to CDW recycling plants hinder practitioners in the construction industry to take the advantage of recycling CDW [4].

CDW that includes concrete, bricks and masonry, wood, and other materials such as glass, insulation, roofing, wires, pipes, rocks, and soil [5], has a significant potential to reuse or recycle. Sorting at source may increase the rates of reuse and recycling [6], the lifespan of landfills [7], and reduce the cost for transportation and disposal [6] and the pollution to the surroundings [8]. Hence, sorting at source and reusing activities for CDW emerge as two beneficial alternatives for the Turkish construction industry. Based on these aforementioned arguments, the objective of the current study was to identify and examine the specific perspective of construction firms about sorting at source and reusing activities in the Turkish construction industry. Toward this aim, a questionnaire survey was applied to construction professionals in Turkey, and the perspective of participants was evaluated extensively.
Consequently, Turkish construction firms' perceptions of sorting at source and reusing were determined and discussed in a detailed manner. As a practical implication, the results obtained may motivate both public authorities and industrial practitioners to improve the current performance of the Turkish construction industry for sorting at source and reusing.

\section{Materials and method}

In this study, a questionnaire survey was conducted with 52 construction professionals working in Turkey. The data gathered were evaluated through a statistical analysis of questions with a 5-point Likert-type scale via SPSS 20. The obtained results were presented in two sub-sections: (i) the demographic information of respondents and (ii) the specific perspective of Turkish construction firms about sorting at source and reusing activities.

\section{Results and discussion}

\subsection{Demographic information}

CDW is a relatively new concept for the Turkish construction industry and related professionals. Therefore, the construction professionals' general approach to CDW and its management issues should be investigated. In order to do that, in the first part of the questionnaire survey, ten questions were asked to participants to reveal the demographic structure of respondents and their companies. The answers given were presented and evaluated extensively in the following parts.

CDW management can be considered as a technical work, and therefore, it should be conducted by technical staff (i.e., civil engineers and architects). Thus, from the perspective of technical staff, the construction industry is significant for better CDW management performance. According to Table 1, 25 civil engineers, 9 architects, and 18 construction technicians participated in the survey. As a result, it can be claimed that job titles of respondents were suitable to fill the questionnaire survey. 
Table 1. Job titles of respondents

\begin{tabular}{ccc}
\hline Title & Frequency & Percentage $(\%)$ \\
\hline Civil engineer & 25 & 48.08 \\
Architect & 9 & 17.31 \\
$\begin{array}{c}\text { Construction } \\
\text { technician }\end{array}$ & 18 & 34.61 \\
\hline
\end{tabular}

The duration of experience in the construction industry leads construction professionals to face with different CDW management applications and/or problems. For this reason, the duration of professional experience of respondents was investigated. As shown in Table 2, a large majority of them $(76.92 \%)$ has been working for at least five years in the Turkish construction industry. Thus, it can be asserted that they are capable and have enough experience to answer the questions. In addition, the duration of experience of respondents' companies were also presented in Table 3. It is clear that all of the participating companies are actively conducting business in the construction industry more than five years (100\%). Therefore, the participating companies can be accepted as appropriate to conduct a survey.

The firms can be classified as (i) micro-scale, (ii) small-scale, (iii), medium-scale, and (iv) largescale according to their annual turnovers of 0-1 million TL, 1-8 million TL, 8-40 million TL, and more than 40 million TL, respectively. Looking at annual average turnovers of the surveyed firms as shown in Table 4, it can be seen that the rate of small-scale firms was $30.76 \%$, that the rate of medium-scale firms was $55.77 \%$, and that largescale firms was $13.47 \%$. These rates seem to be in harmony with the general view of firms in the construction industry, and thus, to be adequate to represent the industry.

There are two types of construction activities according to the amount of waste generation. The first one that generates $\mathrm{CDW}$ up to 2 tons is described as small-scale and the second one that causes more than 2 tons of CDW named as largescale [9]. Over 100 million tons of CDW were recycled or disposed in 2014 in Turkey [10].
Table 2. Duration of professional experience of respondents

\begin{tabular}{ccc}
\hline Duration & Frequency & Percentage $(\%)$ \\
\hline 0-5 years & 12 & 23.08 \\
6-10 years & 18 & 34.62 \\
11-15 years & 10 & 19.23 \\
16-20 years & 7 & 13.46 \\
$>$ 20 years & 5 & 9.61 \\
\hline
\end{tabular}

Table 3. Experience of companies in the construction industry

\begin{tabular}{ccc}
\hline Duration & Frequency & Percentage $(\%)$ \\
\hline 0-5 years & - & - \\
6-10 years & 12 & 23.08 \\
11-15 years & 12 & 23.08 \\
16-20 years & 8 & 15.38 \\
$>$ 20 years & 20 & 38.46 \\
\hline
\end{tabular}

Table 4. Annual average income of respondents' companies

\begin{tabular}{ccc}
\hline Income (TL) & Frequency & Percentage (\%) \\
\hline 0-1 million & - & - \\
1-8 million & 16 & 30.76 \\
8-16 million & 8 & 15.38 \\
16-24 million & 12 & 23.08 \\
24-32 million & 6 & 11.54 \\
32-40 million & 3 & 5.77 \\
$>$ 40 million & 7 & 13.47 \\
\hline *TL: Turkish Lira & &
\end{tabular}

*TL: Turkish Lira

Currently, the definite annual amount of CDW generated in the Turkish construction industry is unknown for 2018. In addition, CDW was generally classified according to the content of waste materials. Therefore, there is a need of classification considering the annual average amount of CDW. In this study, CDW was classified into four groups according to annual average amount of waste. These groups are listed as (i) low (< 100 tons), (ii) moderate (100-1000 tons), (iii) high (1000-5000 tons), and (iv) very high (more than 5000 tons). As Table 5 presents, the CDW 
generation of $32.69 \%$ of firms is low, that of $53.84 \%$ is moderate, that of $5.77 \%$ is high, and that of $7.70 \%$ is very high. These results reveal that every type of waste producer was expressed in the study.

The first regulation, which imposed a legal obligation to CDW producers in order to prepare a CDW management plan, was issued in 2004 in Turkey [9]. In this regulation, CDW waste management is defined as sorting at source, collecting, temporary storage, transportation, reuse, recycle, and storage of CDW and excavated soil. However, the results showed in Table 6 indicate that $42.31 \%$ of respondents' firms have a CDW management plan. Therefore, it can be asserted that both firms that have a CDW management plan and that do not have one were represented in the survey.

In the questionnaire, three different waste disposal options were also asked to participants. A vast majority of respondents $(75.00 \%)$ stated that they dispose their CDWs in landfilling areas, while $19.23 \%$ prefers recycling plants (Table 7). The reason behind this may be the lack of CDW recycling plants in Turkey. Moreover, $36.54 \%$ of respondents rarely can access to a CDW recycling plant, while $30.69 \%$ of them has never had an opportunity (Table 8). This is because, to the best of our knowledge, there are only six CDW recycling plants working actively in Turkey.

There is a need to perform a sorting activity for CDW. However, sorting at plant is not recommended for the environmental protection. On the contrary, sorting at source is an effective medium for several reasons such as reducing the quantities of $\mathrm{CDW}$ and time saving in recycling activities [6]. Time-based sorting is a method in which a time-based collection schedule should be designed for CDW and it requires large spaces in order to store CDW until the collection time. Table 9 presents CDW sorting methods of the surveyed companies. It was found that $19.23 \%$ of respondents prefer sorting at source, that $15.38 \%$ apply time-based sorting, that $21.16 \%$ choose sorting at plant, and that $5.77 \%$ use other methods. However, $38.46 \%$ of participants do not sort CDW generated.
Table 5. Annual average amount of CDW generated by respondents' companies

\begin{tabular}{ccc}
\hline Amount & Frequency & Percentage $(\%)$ \\
\hline$<100$ ton & 17 & 32.69 \\
$100-250$ ton & 11 & 21.15 \\
$250-500$ ton & 11 & 21.15 \\
$500-1000$ ton & 6 & 11.54 \\
$1000-5000$ ton & 3 & 5.77 \\
$>5000$ ton & 4 & 7.70 \\
\hline
\end{tabular}

Table 6. CDW management plan

\begin{tabular}{ccc}
\hline Answer & Frequency & Percentage $(\%)$ \\
\hline Yes & 30 & 57.69 \\
No & 22 & 42.31 \\
\hline
\end{tabular}

Table 7. CDW disposal action

\begin{tabular}{cccc}
\hline Recycling plant & Landfilling & Trash & Other \\
\hline 19.23 & 75.00 & 0.00 & 5.77 \\
\hline
\end{tabular}

Table 8. Accessibility to CDW recycling plants

\begin{tabular}{ccccc}
\hline Always & $\begin{array}{c}\text { Very } \\
\text { Frequently }\end{array}$ & Occasionally & Rarely & Never \\
\hline 0.00 & 0.08 & 32.69 & 36.54 & 30.69 \\
\hline
\end{tabular}

Table 9. CDW sorting methods

\begin{tabular}{ccccc}
\hline $\begin{array}{c}\text { Sorting at } \\
\text { source }\end{array}$ & $\begin{array}{c}\text { Time-based } \\
\text { sorting }\end{array}$ & $\begin{array}{c}\text { Sorting at } \\
\text { plant }\end{array}$ & None & Other \\
\hline 19.23 & 15.38 & 21.16 & 38.46 & 5.77 \\
\hline
\end{tabular}

The generated CDW should be collected in separate portable containers in order to prevent causing any visual pollution and dust [9]. In this context, construction professionals should prepare necessary mediums to collect and store CDW in job sites. The results regarding the use of CDW containers were presented in Table 10. In conclusion, $38.46 \%$ of construction professionals do not use this kind of containers in their waste collection activities. 


\subsection{Perspective of construction firms about sorting at source and reusing activities}

The second part of the questionnaire survey consisted of eight questions with a five -point Likert scale. These questions were prepared to determine the perspective of Turkish construction firms about sorting at source and reusing activities for CDW. To achieve this, the survey was conducted face-to-face with 52 participants, and the results obtained were totally presented in Table 11 .

CDW recycling practices have numerous advantages. For more efficient CDW recycling performance, sorting at source and reusing options should be employed properly. Therefore, construction professionals who will conduct CDW management activities should be aware of the importance of these options. According to Table 11, $82.7 \%$ of respondents agree that practices of CDW producers for sorting at source, collecting, transporting, and disposing of CDW have potential to provide sustainable $\mathrm{CDW}$ management. Furthermore, reducing the volume of waste deposited in landfills has a positive effect on the extension of the life of the existing landfills [11]. Results show that $92.31 \%$ of professionals believe that sorting CDW at source with appropriate processes would be beneficial to extend the life of landfills. In addition, $84.63 \%$ think that sorting at source, reusing, and recycling of the excavation soil can also be advantageous for CDW management applications in terms of sustainability. Moreover, recycling has a positive effect to reduce the demand for the extraction and processing of new aggregate [12]. From this perspective, $86.55 \%$ of participants support the selective demolition method and sorting at source before recycling in order to conduct a better CDW recycling process. Similarly, the use of recovered and recycled materials seems to be beneficial both economically and environmentally for $90.5 \%$ and $92.28 \%$ of respondents, respectively.

CDW shall be collected, transported, and recycled in a systematic way, considering the principals indicated in the Regulation on Control of Excavation Soil and CDW issued by the Turkish Ministry of Forestry in 2004. Generally, CDW is transported with earth-moving trucks to landfills. This is because construction firms do not intend to bear the expense of sorting at source and of transporting to different locations.

Table 10. Perspective of construction firms about sorting at source and reusing activities

\begin{tabular}{|c|c|c|c|c|c|}
\hline Questions & $\begin{array}{l}\text { Strongly } \\
\text { Disagree }\end{array}$ & Disagree & $\begin{array}{l}\text { Partly } \\
\text { Agree }\end{array}$ & Agree & $\begin{array}{c}\text { Strongly } \\
\text { Agree }\end{array}$ \\
\hline $\begin{array}{l}\text { Practices of CDW producers for sorting at source, } \\
\text { collecting, transporting, and disposing of CDW would } \\
\text { be beneficial. }\end{array}$ & 5.77 & 11.53 & 17.34 & 46.15 & 19.21 \\
\hline $\begin{array}{l}\text { Starting from recyclable materials, sorting CDW at } \\
\text { source with appropriate processes would be beneficial. }\end{array}$ & 1.92 & 5.77 & 19.21 & 50.00 & 23.10 \\
\hline $\begin{array}{l}\text { Sorting at source, reusing, and recycling of the } \\
\text { excavation soil would be beneficial. }\end{array}$ & 3.84 & 11.53 & 15.38 & 46.15 & 23.10 \\
\hline $\begin{array}{l}\text { Applying selective demolition method and sorting at } \\
\text { source before recycling would be beneficial. }\end{array}$ & 1.92 & 11.53 & 13.45 & 50.00 & 23.10 \\
\hline $\begin{array}{l}\text { The use of materials recovered with selective } \\
\text { demolition would be beneficial economically and } \\
\text { environmentally. }\end{array}$ & 3.84 & 5.77 & 19.21 & 42.32 & 28.86 \\
\hline $\begin{array}{l}\text { The use of recycled materials would be beneficial both } \\
\text { economically and environmentally. }\end{array}$ & 3.84 & 3.84 & 38.45 & 38.45 & 15.38 \\
\hline $\begin{array}{l}\text { Collecting the sorted CDW from construction site by } \\
\text { the relevant local authority and using them in the } \\
\text { recycling process would be beneficial. }\end{array}$ & 3.84 & 11.53 & 21.15 & 36.54 & 26.94 \\
\hline $\begin{array}{l}\text { Providing financial incentives for construction firms } \\
\text { that contribute to recycling and recovering of CDW } \\
\text { would be beneficial. }\end{array}$ & 7.69 & 7.69 & 25.00 & 36.52 & 23.10 \\
\hline
\end{tabular}


However, according to $84.63 \%$ of participants, the collection of the sorted CDW from job sites by the relevant local authority and using them in the recycling process would encourage construction professionals to practicing on-site sorting of CDW. In Turkey, there are some financial incentives that were issued by the government, but these incentives are usually based on the regional population density. Therefore, construction firms which operate in the regions where the population is low may have difficulties to take advantage of these incentives. Finally, $84.62 \%$ of respondents believe that providing financial incentives for construction firms that contribute to recycling and recovering of CDW may help for the dissemination of these kinds of activities across all stakeholders of the Turkish construction industry.

\section{Conclusion}

The CDW management will always be a major issue for the construction industry due to its environmentally hazardous nature. However, proper CDW management practices may decrease harmful effects of the industry. In this respect, sorting at source and reusing activities of CDWs have a vital role to provide the sustainable built environment. Therefore, this study presented the current situation of the perspective of construction firms about sorting at source and reusing activities in Turkey. According to findings, for Turkish construction firms, (i) having a CDW management plan is not common, (ii) using landfills to dispose the waste generated is popular, (iii) accessing to CDW recycling plants is very limited, (iv) sorting at source practices are rare, and lastly (v) sorting CDW in separate containers is not preferred. However, construction professionals have a positive approach on sorting at source and reusing of CDW. A vast majority of participants agree that sorting at source, reusing, and recycling of CDW and the excavation soil as well as the selective demolition method before recycling have great potential to provide a sustainable CDW management plan. However, waste disposal to landfills is a general behavior for construction firms. This controversy indicates that most of the construction professionals knows the right practices for CDW disposal but generally, they do not conduct the CDW management properly. In order to extend the scope of sorting at source activities and motivate construction firms to prefer to dispose their waste to CDW recycling plants, social consciousness on CDW recycling and usage of recycle materials should be increased. In addition, a public reward system for construction firms using CDW recycling plants may have positive effect on constructions firms. Furthermore, the use of recovered and/or recycled materials seems to be beneficial environmentally and economically. Finally, the financial and physical supports of local authorities seem to be important for the dissemination of CDW management applications in Turkey.

The results obtained may create awareness on the Turkish construction industry about the significance of sorting at source and reusing of CDW in Turkey. Similarly, the gap in the literature for this issue can be filled through the current study. In addition, the Turkish CDW recycling industry may benefit from the results of the study in order to provide a holistic approach to the CDW management.

\section{Acknowledgements}

The authors gratefully acknowledge the surveyed respondents for their generous collaboration and contributions. The authors also thank the financial support provided by the Committee on Research Grants of Zonguldak Bulent Ecevit University.

\section{References}

[1] Tam VWY, Tam CM (2006). A review on the viable technology for construction waste recycling. Resources, Conservation and Recycling, 47, 20922.

[2] Wang J, Yuan H, Kang X, Lu W (2010). Critical success factors for on-site sorting of construction waste: A China study. Resources, Conservation and Recycling, 54, 931-936.

[3] Peng CL, Scorpio DE, Kitbert CJ (1997). Strategies for successful construction and demolition waste recycling operations. Construction Management and Economics, 15(1), 49-58. 
[4] Ulubeyli S, Kazaz A, Arslan V (2017). Construction and demolition waste recycling plants revisited: management issues. Procedia Engineering, 172, 1190-1197.

[5] Coventry S, Wolveridge C, Hillier S. The Reclaimed and Recycled Construction Materials Handbook. Construction Industry Research and Information Association, UK, 1999.

[6] Poon CS, Ann TW, Ng LH (2001). On-site sorting of construction and demolition waste in Hong Kong. Resources, Conservation and Recycling, 32, 157-172.

[7] Hao JL, Hills MJ, Shen LY (2008). Managing construction waste on site through system dynamic modeling: the case of Hong Kong. Engineering, Construction and Architectural Management, 15(2), 103-13.

[8] Shen LY, Tam VWY, Tam CM, Drew D (2004). Mapping approach for examining waste management on construction sites. Journal of Construction Engineering and Management, 130(4), 472-81.

[9] MEF. Regulation on control of excavation soil, construction and demolition waste. Ministry of Environment and Forestry. Issue of Official Gazette: 25406, 2004.

[10] MEU. National waste management action plan 2023. Ministry of Environment and Urbanization, 2018.

[11] Tech Data Sheet. Recycling spent sandblasting grit and similar wastes as aggregate in asphaltic concrete. Naval Facilities Engineering Service Center. Port Hueneme. California, 1998.

[12] Carneiro AP, Cassa JC, DeBrum IA, Vieira AM, Costa ADB, Sampaio TS, Alberte EPV. Construction waste characterization for production of recycled aggregate - Salvador / Brazil. International Conference on the Science and Engineering of Recycling for Environmental Protection, 31 May 1-2 June 2000, Harrogate, England. 